\title{
Simple Insole for Dynamic Foot Plantar Measurement in Walking Gait Analysis Using Force Sensitive Resistor
}

\author{
${ }^{1}$ Muhammad Abdul Wahid, ${ }^{2}$ Scharta Saragih, ${ }^{3}$ Dwi Basuki Wibowo, ${ }^{4}$ Ismoyo Haryanto \\ ${ }^{1,2,3,4}$ Mechanical Engineering Department, Diponegoro University, J1. Prof. Sudarto No.13, Tembalang, Semarang, 50275 \\ Indonesia
}

\begin{abstract}
There are 2 types of footprint scanning, namely scanning is not burdened and burdened. The pressure distribution on the soles of the feet depends on many factors such as body mass index (BMI, $\mathrm{kg} / \mathrm{m} 2$ ), sex, foot contact area or foot type and daily activities. Measuring the pressure distribution in the soles of the feet is done to help in orthotic shoes for sufferers on the soles of the feet and certain sports shoes. For this purpose, we must know the parts of the foot that receive a large load when walking, running well. The human foot is divided into 3 parts, namely the top, middle and back. The purpose of this study is to improve and conduct testing to study the distribution of the soles of the feet both while walking and then carrying out the validation of the results of the assessment with several studies that have been done by previous researchers. In this study to study the pressure distribution on the feet, the insole has been placed 24 sensors (12 sensors on each foot). Sensor data will approve with microcontroller, and the final results are shown using special software. Tests data were obtained from 10 subjects with foot size 40 and body mass varying. Tests are performed when 1 running cycle consists of 4 phases, namely heel strike, loading response, terminal position, and preswing.
\end{abstract}

Keywords: Pressure Distribution, FSR, Gait Analysis.

\section{INTRODUCTION}

There are 2 types of footprint scanning, namely scanning is not burdened (unloaded) and burdened (loaded).An unloaded scan is performed using a 3D scanner that produces the contours of the sole of the foot. This type of scan is intended, among other things, to estimate the deformation of the sole of the foot when standing [1], insole design (shoe insole) with contour shape [2], and evaluating of foot type (flat foot or high $\operatorname{arch})[3]$.

There are 2 types of loaded foot scans, namely scans that are intended only to determine the $2 \mathrm{D}$ shape of the soles of the feet and to determine the distribution of pressure on the soles of the feet when standing or walking. The first type of scan, commonly called footprint scanning, is aimed at determining shoe size [4], evaluating the type of foot, estimating the sex and height of the perpetrator from the footprints left behind, and identifying ancient animal species [5]. Specific-load scanning of the sole of the foot in its two fields of study is called pedobarography. The measuring instrument is usually called a force plate. The results of these pedobarography measurements are very useful to determine the distribution of the load on the sole of the left/right foot in post-amputation diabetic patients, to determine the effect of standing posture on the distribution of the load on the soles of the feet, to determine the type of sole of the foot and its effect on the distribution of the load on the feet. the sole of the foot, to help design orthotic shoes for people with calcaneal spur (growth of a needle in the heel bone) [3], and to determine behavior and performance when walking and running (gait analysis).

This study aims to design simple insole for dynamic foot plantar measurement. Number of sensors, material and methods are adapted from another researcher before. For validation this tool is tested on walking activities.

\section{MATERIAL AND METHODS}

Device consist of 24 sensor will be place on each insole (12 on left and 12 on right side). Sensor is FSR-400 series are made by Interlink Electronics with $0,46 \mathrm{~mm}$ thickness and $12.7 \mathrm{~mm}$ diameter of measuring area. It can be sensitive from 100 gram until $10 \mathrm{~kg}$ or $1.5-150 \mathrm{psi}$ in pressure. Before use, the sensor is calibrated with a maximum load of $6 \mathrm{~kg}(6000$ grams). This selection is based on the results of previous studies using the same type of sensor. The calibration results can be shown in Table 1 .

Table 1: Voltage (V) Measurement result base on load (gram)

\begin{tabular}{|c|c|}
\hline Load (gram) & $\begin{array}{c}\text { Voltage } \\
\text { (Volt) }\end{array}$ \\
\hline 0 & 0 \\
\hline 100 & 0.469 \\
\hline 200 & 0.665 \\
\hline 400 & 0.865 \\
\hline 500 & 1.109 \\
\hline 800 & 1.383 \\
\hline 1000 & 1.505 \\
\hline 1500 & 1.737 \\
\hline 2000 & 1.843 \\
\hline 2500 & 1.911 \\
\hline 3000 & 1.955 \\
\hline 3500 & 2.038 \\
\hline
\end{tabular}


ISSN (online): 2581-3048

\begin{tabular}{|l|l|}
\hline 4000 & 2.157 \\
\hline 4500 & 2.258 \\
\hline 5000 & 2.317 \\
\hline 5500 & 2.35 \\
\hline 6000 & 2.39 \\
\hline
\end{tabular}

The relationship between load and voltage measurements can be seen in Figure 1. The results of the validation were carried out using a polynomial approach so that the following results were obtained:

$$
L=927.7757 V^{3}-1643.867 V^{2}+1083.49 V-31.02378
$$

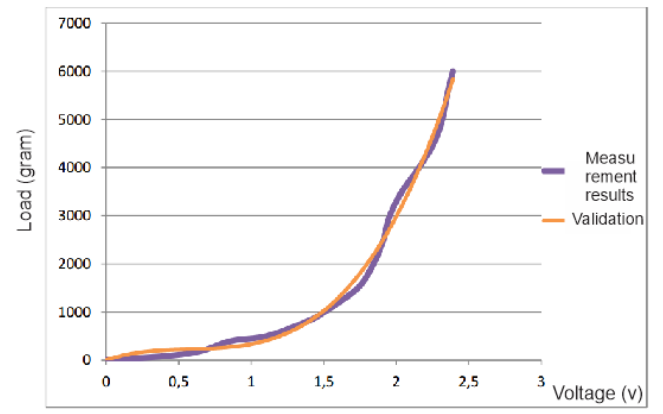

Figure 1: Relationship between Load (gram) and Voltage (V)

The insole is made of foam or silicon material with flat contours, $3 \mathrm{~mm}$ thick and has a foot size of 40 . A total of 24 sensors are placed based on Figure 2. In more detail using the coordinate system in Table 2. Sensor placement refers to research that has been done by Albon [6].

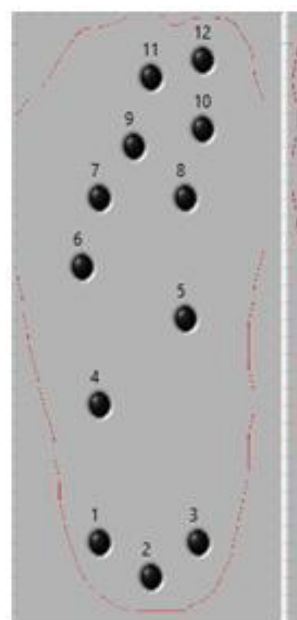

(a)

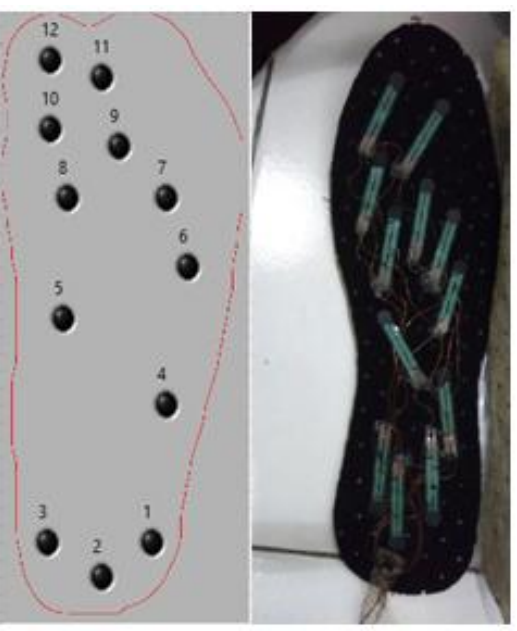

(b)
Figure 2: (a) Simple Insole for Dynamic Foot Plantar Measurement; (b) Location FSR placement

Table 2: Coordinate of FSR Placement

\begin{tabular}{|c|c|c|c|c|}
\hline \multirow{2}{*}{ Sensor } & \multicolumn{2}{|c|}{ Left } & \multicolumn{2}{c|}{ Right } \\
\cline { 2 - 5 } & $\mathbf{x}$ & $\mathbf{y}$ & $\mathbf{x}$ & $\mathbf{y}$ \\
\hline 1 & 8.6 & 4.1 & -8.6 & 4.1 \\
\hline 2 & 6.2 & 2.5 & -6.2 & 2.5 \\
\hline
\end{tabular}

\begin{tabular}{|c|c|c|c|c|}
\hline 3 & 3.6 & 4.1 & -3.6 & 4.1 \\
\hline 4 & 9.3 & 10.6 & -9.3 & 10.6 \\
\hline 5 & 4.4 & 14.6 & -4.4 & 14.6 \\
\hline 6 & 10.4 & 17.0 & -10.4 & 17.0 \\
\hline 7 & 9.3 & 20.2 & -9.3 & 20.2 \\
\hline 8 & 4.6 & 20.2 & -4.6 & 20.2 \\
\hline 9 & 7.1 & 22.6 & -7.1 & 22.6 \\
\hline 10 & 4.0 & 23.2 & -4.0 & 23.2 \\
\hline 11 & 6.2 & 25.8 & -6.2 & 25.8 \\
\hline 12 & 3.8 & 26.6 & -3.8 & 26.6 \\
\hline
\end{tabular}

The voltage on the FSR sensor is read by the Arduino Mega 2560 microcontroller. The data transmission system from each microcontroller (left and right) to the computer uses a USB serial cable through the communication port. Before being sent to the software interface, it is processed using a LabView-based DAQ. Furthermore, the data will be visualized via a computer monitor, see Figure 3.

\begin{tabular}{|c|c|c|c|c|}
\hline FSR Sensors & $\begin{array}{c}\text { Arduino Mega } \\
2560\end{array}$ & DAQ & Interface & $\begin{array}{c}\text { Display } \\
\text { Computer }\end{array}$ \\
\hline
\end{tabular}

Figure 3: Block diagram system of dynamically load gauge insole

Sensor data readings are presented and packaged with a Graphical User Interface (GUI). The sensor value is displayed with an LED display in the middle area and the real value on the left and right sides. The sensor LED will change color as the voltage reading value changes. The minimum value is shown in blue and the maximum value is shown in red, see Figure 4.

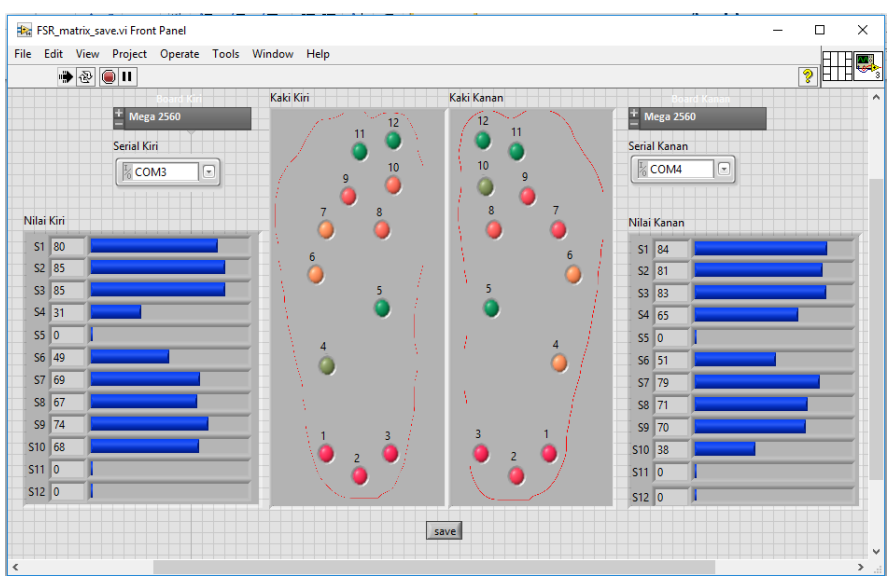

Figure 4: Graphical User Interface (GUI) of dynamically foot plantar measurement software

The next stage is the insole is inserted into a pair of shoes that are used when testing the activity of one walking cycle. The data collection stage is carried out in the heel strike, loading response, terminal stance and preswing phases (see at Figure 4). Data collection can be shown in Figure 5. 
ISSN (online): 2581-3048

\section{IRJIET}

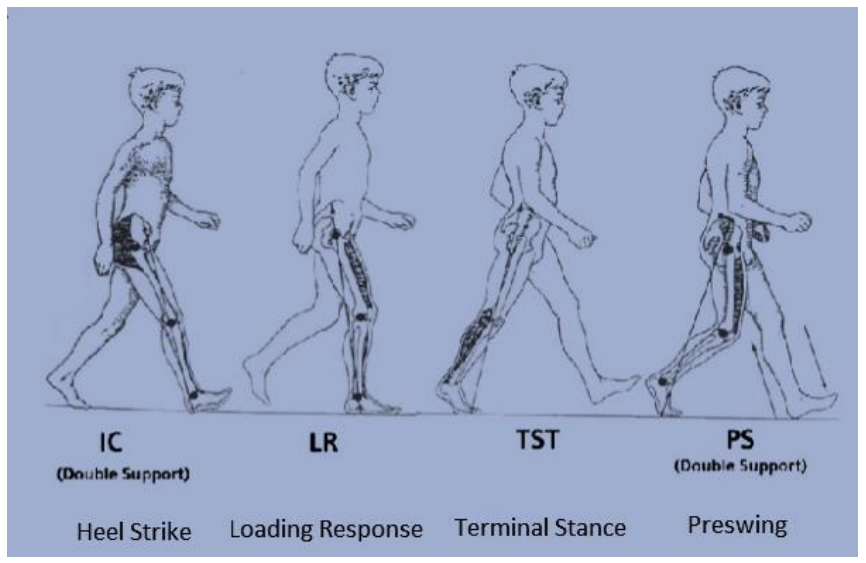

Figure 5: Walking phase: heel strike, loading response, terminal stance, preswing

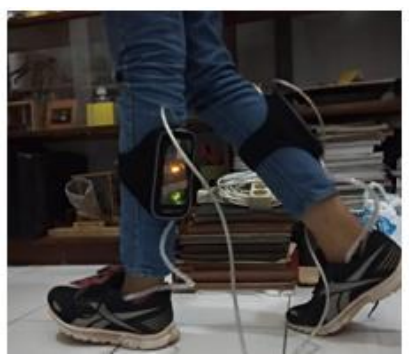

(a)

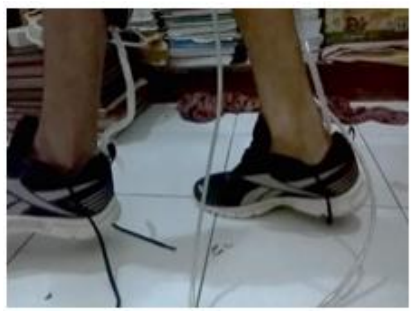

(c)

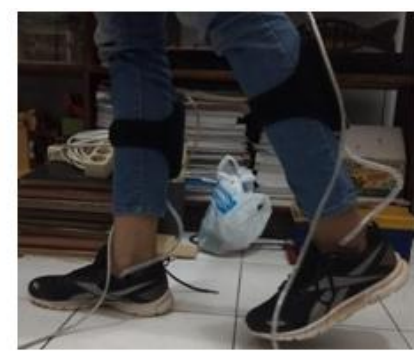

(b)

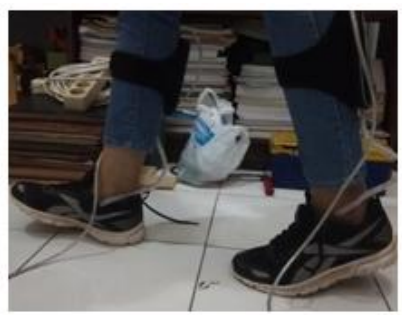

(d)

Figure 6: Example data collection process each of phase; (a) Heel strike; (b) Loading response; (c) Terminal Stance and (d) Preswing

\section{RESULTS AND DISCUSSIONS}

Measurements were carried out by involving 10 correspondent people with foot size 40 and varying weight. Correspondent detail data can be seen in Table 3. FL, FW and Foot Area values obtained from testing using footprint.

Table 3: Correspondence data of measurement

\begin{tabular}{|c|c|c|c|c|c|}
\hline No & $\begin{array}{c}\text { Weight } \\
(\mathbf{k g})\end{array}$ & BMI & $\begin{array}{c}\text { Footh } \\
\text { Length } \\
(\mathbf{m m})\end{array}$ & $\begin{array}{c}\text { Footh } \\
\text { Wide } \\
(\mathbf{m m})\end{array}$ & $\begin{array}{c}\text { Foot } \\
\text { Area } \\
\mathbf{( m m}^{\mathbf{2}}\end{array}$ \\
\hline 1 & 47 & 17,70 & 238,44 & 128,05 & 9583,11 \\
\hline 2 & 45 & 17,57 & 232,72 & 93,75 & 8961,63 \\
\hline 3 & 51 & 18,29 & 235,26 & 92,10 & 8538,40 \\
\hline 4 & 63 & 23,71 & 233,87 & 99,21 & 11422,41 \\
\hline 5 & 75 & 31,22 & 227,51 & 91,08 & 10934,17 \\
\hline 6 & 72 & 26,45 & 226,88 & 88,54 & 7789,68 \\
\hline
\end{tabular}

Volume 5, Issue 11, pp 57-61, November-2021

https://doi.org/10.47001/IRJIET/2021.511010

\begin{tabular}{|c|c|c|c|c|c|}
\hline 7 & 61 & 22,96 & 265,62 & 136,69 & 13748,14 \\
\hline 8 & 47 & 19,56 & 226,88 & 88,54 & 9976,04 \\
\hline 9 & 64 & 26,30 & 219,19 & 89,13 & 519,19 \\
\hline 10 & 56 & 22,43 & 221,92 & 96,80 & 11353,09 \\
\hline
\end{tabular}

Data collection includes the heel strike, loading response, terminal stance and preswing phases. The results of measuring the distribution of foot load on walking activities in each phase in detail can be seen in Tables 3,4,5 and 6 .

Table 4: Load Distribution at heel strike phase

\begin{tabular}{|c|c|c|c|c|c|c|c|c|c|c|c|c|c|}
\hline \multirow{2}{*}{$\begin{array}{c}\text { No } \\
\text { Subject }\end{array}$} & Foot \\
$\mathbf{R} / \mathbf{L})$ & \multicolumn{10}{|c|}{ Results of Sensors Data Test (gram) } \\
\hline & & $\mathbf{1}$ & $\mathbf{2}$ & $\mathbf{3}$ & $\mathbf{4}$ & $\mathbf{5}$ & $\mathbf{6}$ & $\mathbf{7}$ & $\mathbf{8}$ & $\mathbf{9}$ & $\mathbf{1 0}$ & $\mathbf{1 1}$ & $\mathbf{1 2}$ \\
\hline 1 & Left & 850 & 860 & 850 & 0 & 0 & 0 & 0 & 0 & 0 & 0 & 0 & 0 \\
\hline & Right & 0 & 0 & 0 & 0 & 0 & 380 & 790 & 800 & 790 & 710 & 820 & 570 \\
\hline 2 & Left & 860 & 860 & 780 & 0 & 0 & 0 & 0 & 0 & 0 & 0 & 0 & 0 \\
\hline & Right & 0 & 0 & 0 & 0 & 0 & 230 & 710 & 750 & 720 & 720 & 600 & 600 \\
\hline 3 & Left & 850 & 870 & 860 & 0 & 0 & 0 & 0 & 0 & 0 & 0 & 0 & 0 \\
\hline & Right & 0 & 0 & 0 & 0 & 0 & 400 & 720 & 750 & 780 & 830 & 790 & 450 \\
\hline 4 & Left & 890 & 880 & 890 & 0 & 0 & 0 & 0 & 0 & 0 & 0 & 0 & 0 \\
\hline & Right & 0 & 0 & 0 & 0 & 0 & 450 & 760 & 790 & 830 & 820 & 820 & 750 \\
\hline 5 & Left & 910 & 890 & 880 & 0 & 0 & 0 & 0 & 0 & 0 & 0 & 0 & 0 \\
\hline & Right & 0 & 0 & 0 & 0 & 0 & 490 & 840 & 790 & 850 & 820 & 800 & 790 \\
\hline 6 & Left & 890 & 850 & 880 & 0 & 0 & 0 & 0 & 0 & 0 & 0 & 0 & 0 \\
\hline & Right & 0 & 0 & 0 & 0 & 0 & 560 & 800 & 840 & 810 & 770 & 780 & 800 \\
\hline 7 & Left & 900 & 870 & 890 & 0 & 0 & 0 & 0 & 0 & 0 & 0 & 0 & 0 \\
\hline & Right & 0 & 0 & 0 & 0 & 0 & 310 & 660 & 710 & 770 & 760 & 800 & 770 \\
\hline 8 & Left & 850 & 820 & 880 & 0 & 0 & 0 & 0 & 0 & 0 & 0 & 0 & 0 \\
\hline & Right & 0 & 0 & 0 & 0 & 0 & 380 & 730 & 630 & 790 & 790 & 710 & 650 \\
\hline 9 & Left & 910 & 880 & 890 & 0 & 0 & 0 & 0 & 0 & 0 & 0 & 0 & 0 \\
\hline & Right & 0 & 0 & 0 & 0 & 0 & 460 & 720 & 810 & 750 & 380 & 800 & 740 \\
\hline 10 & Left & 900 & 880 & 720 & 1 & 0 & 0 & 0 & 0 & 0 & 0 & 0 & 0 \\
\hline & Right & 0 & 0 & 0 & 0 & 0 & 510 & 650 & 790 & 780 & 810 & 790 & 770 \\
\hline
\end{tabular}

Table 4 shows that the load that occurs is on the front of the right leg (sensors 6-12) and the back of the left leg (sensors 1-3). The maximum load in this phase is 900 grams.

Table 5: Load Distribution at loading response phase

\begin{tabular}{|c|c|c|c|c|c|c|c|c|c|c|c|c|c|}
\hline \multirow{2}{*}{$\begin{array}{c}\text { No } \\
\text { Subject }\end{array}$} & \multirow{2}{*}{$\begin{array}{l}\text { Foot } \\
\text { (R/L) }\end{array}$} & \multicolumn{12}{|c|}{ Results of Sensors Data Test (gram) } \\
\hline & & 1 & 2 & 3 & 4 & 5 & 6 & 7 & 8 & 9 & 10 & 11 & 12 \\
\hline & Left & 790 & 750 & 850 & 840 & 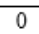 & 760 & 790 & 560 & 630 & 670 & 500 & 500 \\
\hline & Right & 0 & 0 & 0 & 0 & 0 & 0 & 0 & 0 & 0 & 0 & 0 & 0 \\
\hline & Left & 860 & 840 & 840 & 780 & 10 & 760 & 770 & 690 & 540 & 650 & 450 & 490 \\
\hline & Right & 0 & 0 & - & - & 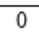 & 0 & 0 & 0 & 0 & 0 & 0 & 0 \\
\hline & Left & 830 & 840 & 850 & 700 & 0 & 780 & 810 & 740 & 690 & 630 & 480 & 510 \\
\hline & Right & 0 & 0 & 0 & 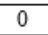 & 0 & 0 & 0 & 0 & 0 & 0 & 0 & 0 \\
\hline & Left & 890 & 880 & 900 & 660 & 10 & 740 & 800 & 650 & 580 & 770 & 610 & 720 \\
\hline & Right & 0 & 0 & 0 & 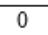 & 0 & 0 & 0 & 0 & 0 & 0 & 0 & 0 \\
\hline & Left & 900 & 860 & 890 & 840 & 0 & 790 & 830 & 740 & 620 & 820 & 590 & 640 \\
\hline & Right & 0 & 0 & 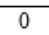 & 0 & & $\sigma$ & 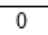 & 0 & 0 & 0 & 0 & 0 \\
\hline & Left & 880 & 690 & 860 & 790 & 10 & 720 & 820 & 760 & 700 & 830 & 640 & 780 \\
\hline & Right & 0 & 0 & 0 & 0 & 0 & 0 & 0 & 0 & 0 & 0 & 0 & 0 \\
\hline & Left & 900 & 830 & 880 & 830 & 0 & 780 & 790 & 640 & 560 & 780 & 600 & 710 \\
\hline & Right & 0 & 0 & 0 & 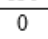 & 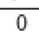 & 0 & 0 & 0 & 0 & 0 & 0 & 0 \\
\hline & Left & 760 & 650 & 880 & 840 & 0 & 750 & 820 & 790 & 770 & 770 & 21 & 380 \\
\hline & Right & 0 & 0 & 0 & 0 & 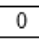 & 0 & 0 & 0 & 0 & 0 & 0 & 0 \\
\hline & Left & 850 & 750 & 870 & 850 & 0 & 800 & 860 & 800 & 730 & 720 & 590 & 520 \\
\hline & Right & 0 & 0 & 0 & 0 & 0 & 0 & 0 & 0 & 0 & 0 & 0 & 0 \\
\hline \multirow[t]{2}{*}{10} & Left & 890 & 840 & 710 & 710 & 10 & 700 & 790 & 790 & 720 & 690 & 530 & 500 \\
\hline & Right & 0 & 0 & 0 & 0 & 0 & 0 & 0 & 0 & 0 & 0 & 0 & 0 \\
\hline
\end{tabular}

Table 5 shows that the load that occurs in this phase is evenly distributed over the entire area of the left foot. On the 
right foot there is no load because the foot does not touch the floor. The maximum load on the back area of the left foot is 900 grams.

Table 6: Load Distribution at terminal stance phase

\begin{tabular}{|c|c|c|c|c|c|c|c|c|c|c|c|c|c|}
\hline \multirow{2}{*}{$\begin{array}{c}\text { No } \\
\text { Subject }\end{array}$} & \multirow{2}{*}{$\begin{array}{l}\text { Foot } \\
(R / L)\end{array}$} & \multicolumn{12}{|c|}{ Results of Sensors Data Test (gram) } \\
\hline & & 1 & 2 & 3 & 4 & 5 & 6 & 7 & 8 & 9 & 10 & 11 & 12 \\
\hline \multirow[t]{2}{*}{1} & Left & 0 & 0 & 0 & & 10 & 790 & 840 & 830 & 840 & 850 & 660 & 820 \\
\hline & Right & 0 & $v$ & 0 & & 0 & 0 & 0 & 0 & 0 & 0 & 0 & 0 \\
\hline \multirow[t]{2}{*}{2} & Left & 0 & 0 & 0 & & 20 & 780 & 880 & 820 & 830 & 780 & 740 & 530 \\
\hline & Right & 0 & 0 & 0 & & 0 & 0 & 0 & 0 & 0 & 0 & 0 & 0 \\
\hline \multirow[t]{2}{*}{3} & Left & 0 & 0 & 0 & 0 & 10 & 800 & 830 & 830 & 810 & 860 & 720 & 830 \\
\hline & Right & 0 & 0 & 0 & & 0 & 0 & 0 & 0 & 0 & 0 & 0 & 0 \\
\hline \multirow[t]{2}{*}{4} & Left & 0 & 0 & 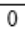 & 0 & 10 & 790 & 880 & 870 & 870 & 860 & 870 & 850 \\
\hline & Right & 0 & 0 & 0 & 0 & 0 & 0 & 0 & 0 & 0 & 0 & 0 & 0 \\
\hline \multirow[t]{2}{*}{5} & Left & 0 & 0 & 0 & 0 & 10 & 830 & 890 & 880 & 870 & 850 & 840 & 870 \\
\hline & Right & 0 & 0 & 0 & 0 & 0 & 0 & 0 & 0 & 0 & 0 & 0 & 0 \\
\hline \multirow[t]{2}{*}{6} & Left & 0 & 0 & 0 & 0 & 20 & 790 & 890 & 850 & 880 & 880 & 860 & 850 \\
\hline & Right & 0 & 0 & 0 & 0 & 0 & 0 & 0 & 0 & 0 & 0 & 0 & 0 \\
\hline \multirow[t]{2}{*}{7} & Left & 0 & 0 & 0 & 0 & 10 & 800 & 880 & 850 & 850 & 870 & 830 & 780 \\
\hline & Right & 0 & 0 & 0 & 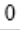 & 0 & 0 & 0 & 0 & 0 & 0 & 0 & 0 \\
\hline \multirow[t]{2}{*}{8} & Left & 0 & 0 & 0 & 0 & 10 & 800 & 880 & 860 & 870 & 730 & 650 & 480 \\
\hline & Right & 0 & 0 & 0 & 0 & 0 & 0 & 0 & 0 & 0 & 0 & 0 & 0 \\
\hline \multirow[t]{2}{*}{9} & Left & 0 & 0 & 0 & 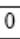 & 10 & 780 & 900 & 870 & 880 & 840 & 820 & 770 \\
\hline & Right & 0 & 0 & 0 & 0 & 0 & 0 & 0 & 0 & 0 & 0 & 0 & 0 \\
\hline \multirow[t]{2}{*}{10} & Left & 0 & 0 & 0 & 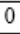 & 20 & 780 & 890 & 880 & 880 & 830 & 830 & 680 \\
\hline & Right & 0 & 0 & 0 & 0 & 0 & 0 & 0 & 0 & 0 & 0 & 0 & 0 \\
\hline
\end{tabular}

Table 6 shows that the load that occurs is in this phase on the toe of the left foot. On the right leg there is still no load because the foot does not touch the floor. The maximum load in this phase is 900 grams.

Table 7: Load Distribution at preswing phase

\begin{tabular}{|c|c|c|c|c|c|c|c|c|c|c|c|c|c|}
\hline \multirow{2}{*}{$\begin{array}{c}\text { No } \\
\text { Subject }\end{array}$} & \multirow{2}{*}{$\begin{array}{l}\text { Foot } \\
\text { (R/L) }\end{array}$} & \multicolumn{12}{|c|}{ Results of Sensors Data Test (gram) } \\
\hline & & 1 & 2 & 3 & 4 & 5 & 6 & 7 & 8 & 9 & 10 & 11 & 12 \\
\hline \multirow[t]{2}{*}{1} & Left & 0 & 0 & 0 & 0 & 0 & 10 & 750 & 800 & 810 & 830 & 710 & 620 \\
\hline & Right & 820 & 880 & 830 & 0 & 0 & 0 & 0 & 0 & 0 & 0 & 0 & 0 \\
\hline \multirow[t]{2}{*}{2} & Left & 0 & 0 & 0 & 0 & 0 & 20 & 780 & 810 & 820 & 790 & 580 & 630 \\
\hline & Right & 850 & 880 & 760 & 0 & 0 & 0 & 0 & 0 & 0 & 0 & 0 & 0 \\
\hline \multirow[t]{2}{*}{3} & Left & 0 & 0 & 0 & 0 & 0 & 10 & 840 & 780 & 700 & 780 & 690 & 800 \\
\hline & Right & 860 & 870 & 850 & 0 & 0 & 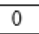 & 0 & 0 & 0 & 0 & 0 & 0 \\
\hline \multirow[t]{2}{*}{4} & Left & 0 & 0 & 0 & 0 & 0 & 0 & 830 & 810 & 830 & 820 & 700 & 810 \\
\hline & Right & 880 & 880 & 880 & 0 & 0 & 0 & 0 & 0 & 0 & 0 & 0 & 0 \\
\hline \multirow[t]{2}{*}{5} & Left & 0 & 0 & 0 & 0 & 0 & 0 & 870 & 870 & 860 & 820 & 720 & 850 \\
\hline & Right & 870 & 900 & 890 & 0 & 0 & 0 & 0 & 0 & 0 & 0 & 0 & 0 \\
\hline & Left & 0 & 0 & 0 & 0 & 0 & 20 & 850 & 84 & 870 & 880 & 550 & 770 \\
\hline & Right & 840 & 890 & 880 & 0 & 0 & 0 & 0 & 0 & 0 & 0 & 0 & 0 \\
\hline \multirow[t]{2}{*}{7} & Left & 0 & 0 & 0 & 0 & 0 & 20 & 830 & 800 & 770 & 850 & 620 & 790 \\
\hline & Right & 860 & 890 & 880 & 0 & 0 & 0 & 0 & 0 & 0 & 0 & 0 & 0 \\
\hline & Left & 0 & 0 & 0 & 0 & 0 & 0 & 760 & 790 & 860 & 880 & 580 & 670 \\
\hline & Right & 850 & 860 & 860 & 0 & 0 & 0 & 0 & 0 & 0 & 0 & 0 & 0 \\
\hline & Left & 0 & 0 & 0 & 0 & 0 & 10 & 860 & 820 & 870 & 800 & 680 & 720 \\
\hline & Right & 870 & 900 & 880 & 0 & 0 & 0 & 0 & 0 & 0 & 0 & 0 & 0 \\
\hline \multirow[t]{2}{*}{10} & Left & & 0 & 0 & 0 & 0 & 0 & 880 & 860 & 870 & 840 & 770 & 450 \\
\hline & Right & 870 & 870 & 870 & 0 & 0 & 0 & 0 & 0 & 0 & 0 & 0 & 0 \\
\hline
\end{tabular}

Table 7 shows that the load that occurs is in this phase on the toe of the left foot. On the right leg there is still no load because the foot does not touch the floor. The maximum load in this phase is 900 grams.

\section{CONCLUSION}

This insole can be inserting at any kinds of shoes with size 40. It can be shown the load distribution with variant led color sensor and real value. There is four phase in walking activity that collect some data, heel strike, loading response, terminal stance and preswing phase. Maximum load in this test is 900 gram. With dynamically method collected data, it can be applied at several activity, not just walking activity. This design with few number of sensor can be alternative low cost device measurement.

\section{REFERENCES}

[1] Wibowo, D.B., Suprihanto, A., Widodo, A., dan Haryadi, G.D., Estimation of Calcaneal Deformation While Standing from the Boolean Operation Between 3D and Footprint Image and its Comparison With Lateral X-ray. MATEC Web Conferences 2014. 2018

[2] Lee, Yu-Chi, Lin, Gloria and Wang, Mao-Jiun J. Comparing 3D foot scanning with conventional measurement methods. Journal of Foot and Ankle Research 2014, 7:44.

[3] Wibowo, DB., Haryadi, GD., Widodo, A., Rahayu, SP. Correlation of loaded and unloaded foot area with arch index in younger flatfoot. MATEC Web of Conference 135, 00060 (2017).

[4] Bavornrit Chuckpaiwong, James A.Nunley, et al., 2008, "The effect of foot type on in-shoe plantar pressure during walking and running". Gait \& Posture 28 405411, Elsevier Boehm, Raphael. The foot \& the shoe: Measurement \& size. DARCO (Europe) GmbH. June 2015.

[5] Crompton, R.H., Pataky, T.C., et al., 2012, "Human-like external function of the foot, and fully upright gait, confirmed in the 3.66 million year old Laetolihominin footprints by topographic statistics, experimental footprint-formation and computer simulation", J. R. Soc. Interface 9, 707-719.

[6] Albon, T. Plantar Force Distribution for Increasing Heel Height within Women's Shoes. The College of Wooster 2011.

[7] Haryadi, G.D.; Wibowo, D.B.; Ariyanto, M.; Suprihanto, A. Digital Scanning Method for Evaluation of Dimensional Parameters and Identification of Foot Type. Patent No. IDS000002253, 2 April 2019.

\section{AUTHORS BIOGRAPHY}

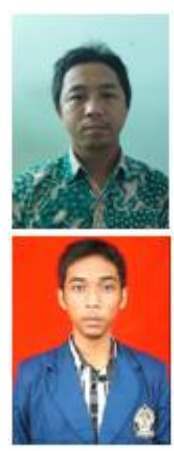

Muhammad Abdul Wahid, Student, Mechanical Engineering Department, Diponegoro University, Indonesia.

Scharta Saragih, Student, Mechanical Engineering Department, Diponegoro University, Indonesia. 


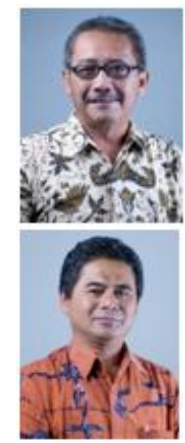

Dwi Basuki Wibowo, Lecturer,

Mechanical Engineering Department,

Diponegoro University, Indonesia.

Ismoyo Haryanto, Lecturer, Mechanical Engineering Department, Diponegoro University, Indonesia.

\section{Citation of this Article:}

Muhammad Abdul Wahid, Scharta Saragih, Dwi Basuki Wibowo, Ismoyo Haryanto, "Simple Insole for Dynamic Foot Plantar Measurement in Walking Gait Analysis Using Force Sensitive Resistor" Published in International Research Journal of Innovations in Engineering and Technology - IRJIET, Volume 5, Issue 11, pp 57-61, November 2021. Article DOI https://doi.org/10.47001/IRJIET/2021.511010 